\title{
Pricing Decision under Dual-Channel Structure considering Fairness and Free-Riding Behavior
}

\author{
Yongmei Liu, Chunjie Ding, Chen Fan, and Xiaohong Chen
}

Business School, Central South University, Changsha, Hunan 410083, China

Correspondence should be addressed to Yongmei Liu; liuyongmeicn@163.com

Received 3 March 2014; Accepted 7 May 2014; Published 26 May 2014

Academic Editor: Fenghua Wen

Copyright (C) 2014 Yongmei Liu et al. This is an open access article distributed under the Creative Commons Attribution License, which permits unrestricted use, distribution, and reproduction in any medium, provided the original work is properly cited.

\begin{abstract}
Under dual-channel structure, the free-riding behavior based on different service levels between online channel and offline channel cannot be avoided, which would lead to channel unfairness. This study implies that the dual-channel supply chain is built up by online channel controlled by manufacturer and traditional channel controlled by retailer, respectively. Under this channel structure, we rebuild the linear demand function considering free-riding behavior and modify the pricing model based on channel fairness. Then the influences of fair factor and free-riding behavior on manufacturer and retailer pricing and performance are discussed. Finally, we propose some numerical analysis to provide some valuable recommendations for manufacturer and retailer improving channel management performance.
\end{abstract}

\section{Introduction}

In the e-commerce era, dual-channel structure composed of direct online channel and traditional retail channel is the first choice for many manufacturers to promote products, which also attracts widespread scholars. In academia, channel pricing is one of the core decision-making problems of dualchannel researches $[1,2]$. In the meantime, decision makers' behaviors are widely concerned in researches $[3,4]$. Due to the differences of channel price and service and so forth, consumers' free-riding behavior based on experience service (or information service) between two channels appears which would affect the decision results of dual-channel pricing.

In dual-channel background, there are two types of freeriding behavior: one is that consumers buy product online but obtain experiential service at physical store and the other is that consumers get information service through network but finally purchase offline [5]. For instance, the experiential products, such as electronic products, household appliances, and cars, have some characteristics like being low in purchase frequency and relatively expensive in price. Consumers usually consult purchasing guiders and attempt to experience product function before they finish their shopping online at more convenient and cheaper channel [6]. As investors tend to measure the risks in the stock market $[7,8]$, some consumers are used to collect product information and consumers' evaluation information online and prefer traditional channel to complete their shopping with low purchase risk $[9,10]$. The development of information technology is helpful for firms to use online channel to create new brands, promote new products, and organize promotional activities frequently. Meanwhile, consumers' ability to get information online is more powerful and information resources are huge online, which will also result in consumers' free-riding behavior based on information services.

In general, service level of traditional channel is higher than that of online channel. Traditional retailer provides quality experiential service offline at high expenses, but manufacturer who controls online channel is the beneficiary because of consumers' free-riding behavior under dualchannel structure. Clearly, due to the impact of free-riding behavior and double marginalization caused by dual-channel competition, retailer is faced with channel unfairness and serious decline in profits. It will increase channel pricing competition, strike a severe blow to the retailer's promotion effort, and deteriorate channels relations [11]. Kumar found that channel fairness was very important to maintain channel relationships through empirical studies $[12,13]$. Fehr and Schmidt indicated that sometimes manufacturers would rather give up a portion of profits in order to achieve channel 
fairness [14]. Researching in supply chain performance, $\mathrm{Wu}$ et al. proposed a more concise fair utility form [15]. Xing et al. analyzed the effect of fairness on the optimal decision of manufacturer and retailer considering dual-channel supply chain [16]. But they ignored the influence of inevitable freeriding behavior on dual-channel pricing strategy and they did not present an appropriate coordination contract to achieve a win-win condition. By using fair utility function, Cui et al. showed that when retailer cared about fairness, manufacturer could use appropriate wholesale price to realize channel coordination [17]. Ho and Zhang [18] and CaliskanDemirag et al. [19] studied the coordination problem of supply chain through fair utility function. Ho and Su investigated ultimatum games with participants concerning peer fairness and found that participants paid attention to both their own income and the ratio of income distribution among the partners [20].

Above all, in the context of dual-channel combined with free-riding behavior, it is worth discussing what pricing decision manufacturer should take to maximize the profits of supply chain and its own and how to coordinate dual-channel supply chain, when concerning the fact that the retailer not only is after profit maximization but also cares whether they are treated fairly.

\section{Basic Assumptions}

The paper assumes that the manufacturer controls the direct online channel and the traditional retailer sells the same product through distributed traditional channel at the same time. Let $i$ be an element of a set of channels, and $i \in$ $\{t, e\}$, where $t$ means traditional channel and $e$ means online channel. Based on Yue and Liu [21], we introduce free-riding behavior effect based on channel service and assume that the demand of traditional channel $Q_{t}$ and online channel $Q_{e}$ is linear function:

$$
\begin{gathered}
Q_{t}=(1-\phi) a-b_{1} p_{t}+\xi_{1} p_{e}+s_{t}+\mu_{t} s_{e} \\
Q_{e}=\phi a-b_{2} p_{e}+\xi_{2} p_{t}+s_{e}+\mu_{e} s_{t} .
\end{gathered}
$$

The basic hypotheses are as follows.

(1) $a$ is the basic market demand; $\phi$ is the market share of online channel, which reflects best-selling extent of product online.

(2) $b_{1}$ is the price elasticity index of product at traditional channel and $b_{2}$ is the price elasticity index of product at online channel, which reflect the price sensitivity of demand for product. $\xi_{1}$ and $\xi_{2}$ are the crossprice elasticity coefficient of product, which reflect the impact of channel price on another channel demand. To simplify the analysis, we suggest that $\xi_{1}=\xi_{2}=$ $\xi$. Combined with reality that the convenience of Internet search makes consumers more sensitive to the price of online channel, we suppose $b_{2}>b_{1}>\xi$.

(3) $s_{t}$ is the service level of traditional channel, including shopping guide service, product presentation, product availability, after-sales service, and high quality shopping environment; $s_{e}$ is the service level of online channel, including product information searching function, customer service online, return service, and promotional advertising service. We refer to the definition of service cost from Tsay and Agrawal [22]. Let the channel service $\operatorname{cost} C_{i}$ be

$$
C_{i}=\frac{1}{2} s_{i}^{2} \quad(i=\{t, e\})
$$

(4) Suppose that the manufacturer is a Stackelberg leader. The decision variables are wholesale price $w$ and online selling price $p_{e}$ (let $p_{e} \geq w$ ). The retailer, who is a follower, decides the traditional channel price $p_{t}$.

In order to ensure that the demand of dual-channel is positive, the online channel price should meet the following condition:

$$
p_{e} \leq \widehat{p}_{e} \triangleq \frac{\xi E+b_{1} F}{b_{1} b_{2}-\xi^{2}}
$$

where

$$
E=(1-\phi) a+s_{t}+\mu_{t} s_{e}, \quad F=\phi a+s_{e}+\mu_{e} s_{t} .
$$

\section{Channel Pricing Strategy without considering Fairness}

3.1. Retailer's Pricing Decision Problem. Without the consideration of fairness, traditional retailer sets profit maximization as his decision-making goal. Given wholesale price $w$ and online channel price $p_{e}$ made by manufacturer, traditional retailer formulates an appropriate traditional channel price $p_{t}$ to maximize its profit function:

$$
\pi_{T}=Q_{t}\left(p_{t}-w-C_{t}\right) .
$$

Proposition 1. The profit function $\pi_{T}$ is the concave function of traditional channel price $p_{t}$.

There is an optimal price $p_{t}^{*}$ to maximize the retailer's profit, and

$$
p_{t}^{*}=\frac{E+b_{1} C_{t}+b_{1} w+\xi p_{e}}{2 b_{1}}
$$

Combining formula (1) and formula (6), we solve partial derivative condition and make it easy to prove that the profit function $\pi_{T}$ is the concave function of traditional channel price $p_{t}$. From formula (7), we can see that optimal traditional channel price $p_{t}^{*}$ increases in traditional channel service $s_{t}$, wholesale price $w$, and online channel price $p_{e}$, respectively. At the same time, the optimal price $p_{t}^{*}$ is also a decreasing function of the price elasticity coefficient $b_{1}$. When consumers feel more sensitive to the price of traditional channel, the traditional retailer will reduce price to increase traditional channel demand. 
3.2. Manufacturer's Pricing Decision Problem. Given the optimal price $p_{t}^{*}$, the manufacturer determines the optimal wholesale price $w$ and online price $p_{e}$ to maximize its profit function:

$$
\pi_{M}=Q_{e} \cdot\left(p_{e}-C_{e}-c\right)+Q_{t} \cdot(w-c) .
$$

The decision-making problem can be described as formula (9), where $c$ is manufacturer's production cost. The proof is shown in Appendix A:

$$
\begin{array}{ll}
\max _{p_{e}, w} & \pi_{M}=Q_{e} \cdot\left(p_{e}-C_{e}-c\right)+Q_{t} \cdot(w-c) \\
\text { s.t. } & p_{e} \geq w \\
& Q_{t}=(1-\phi) a-b_{1} p_{t}+\xi_{1} p_{e}+s_{t}+\mu_{t} s_{e} \\
& Q_{e}=\phi a-b_{2} p_{e}+\xi_{2} p_{t}+s_{e}+\mu_{e} s_{t} .
\end{array}
$$

Proposition 2. There is a critical value of market demand share for online channel:

$$
\begin{aligned}
\widehat{\phi}= & \left(\left(b_{2}-\xi\right)\left(a+s_{t}+\mu_{t} s_{e}\right)+\left(\xi-b_{1}\right)\left(s_{e}+\mu_{e} s_{t}\right)\right. \\
& \left.+\left(\xi^{2}-b_{1} b_{2}\right)\left(C_{t}-C_{e}\right)\right) \\
& \times\left(a\left(b_{1}+b_{2}-2 \xi\right)\right)^{-1} .
\end{aligned}
$$

(1) When manufacturer's online market share satisfies $\phi \geq \widehat{\phi}$, the results of its optimal equilibrium pricing are

$$
\begin{gathered}
p_{e}^{*}=\frac{\xi E+b_{1} F+b_{1} b_{2} C_{e}}{2\left(b_{1} b_{2}-\xi^{2}\right)}+\frac{c}{2}, \\
w^{*}=\frac{b_{2} E+\xi F+\left(\xi^{3} / b_{1}\right) C_{e}}{2\left(b_{1} b_{2}-\xi^{2}\right)}+\frac{c-C_{t}}{2} .
\end{gathered}
$$

(2) When manufacturer's online market share satisfies $\phi<\widehat{\phi}$, the results of its optimal equilibrium pricing are

$$
\begin{aligned}
p_{e}^{*}=w^{*}= & \left(\left(b_{1}+\xi\right) E+2 b_{1} F+b_{1}\left(\xi-b_{1}\right) C_{t}\right. \\
& \left.+\left(2 b_{1} b_{2}-\xi^{2}-b_{1} \xi\right) C_{e}\right) \\
& \left.\times\left(2\left(b_{1}^{2}+2 b_{1} b_{2}-\xi^{2}-2 b_{1} \xi\right)\right)^{-1}\right) \\
+ & \frac{c}{2} .
\end{aligned}
$$

From Proposition 2, we know that if online market share is larger than critical value $\widehat{\phi}$, manufacturer will set wholesale price lower than online channel price $p_{e}$; if online market share is smaller, manufacturer's wholesale price will be equal to online channel price. Put $p_{e}^{*}$ and $w^{*}$ into formula (7); we can calculate retailer's optimal equilibrium pricing. Combining the demand formulas (1) and (2) and the profit formulas (6) and (8), we can obtain the equilibrium demands of dual-channel, as well as the optimal profits of manufacturer and retailer without the consideration of channel fairness.

\section{Channel Pricing Strategy considering Fairness}

4.1. Retailer's Pricing Decision Problem. When retailer not only focuses on its own profit but also cares about the fairness of channel relationship, its decision-making goal turns into the perceived utility maximization. The retailer's perceived utility $U_{T}$ concerning fairness is composed of two parts: profit $\pi_{T}$ (formula (6)) and fairness utility $f_{T}$. Reviewing the existing researches of fairness utility definition [14, 17], we define fairness utility $f_{T}$ function as

$$
\begin{aligned}
f_{T}= & -\alpha \max \left\{\gamma(w-c) Q_{t}-\pi_{T}, 0\right\} \\
& -\beta \max \left\{\pi_{T}-\gamma(w-c) Q_{t}, 0\right\} .
\end{aligned}
$$

$\gamma$ is profit distribution ratio at traditional channel, namely, retailer's channel fairness goal. The bigger $\gamma$ means that retailer is more powerful in this dual-channel supply chain. $\alpha$ implies that when retailer encounters disadvantageous channel unfairness, its fairness utility will decline $\alpha$ times of the profit difference between manufacturer and retailer in traditional channel; $\beta$ means that when retailer is faced with advantageous channel unfairness, the fairness utility will decline $\beta$ times of the profit difference in traditional channel. Fairness parameters $(\alpha, \beta, \gamma)$ satisfy $\alpha \geq \beta, 0 \leq \beta<1$, and $\gamma>0$. We suppose that manufacturer and retailer all have symmetric information.

If retailer's profits do not reach $\gamma$ times of manufacturer's wholesale incomes in the traditional channel, which means $\gamma(w-c) Q_{t}>\pi_{T}$, then retailer encounters disadvantageous channel unfairness. In this case, the retailer's perceived fairness utility is $-\alpha\left[\gamma(w-c) Q_{t}-\pi_{T}\right]$, and its pricing decision problem can be described as

$$
\begin{array}{ll}
\max _{p_{t}} & U_{T}=\pi_{T}+f_{T} \\
\text { s.t. } & \pi_{T}=Q_{t}\left(p_{t}-w-C_{t}\right) \\
& f_{T}=-\alpha\left[\gamma(w-c) Q_{t}-\pi_{T}\right] \\
& \gamma(w-c) Q_{t} \geq Q_{t}\left(p_{t}-w-C_{t}\right) .
\end{array}
$$

If retailer's profits are not less than $\gamma$ times of manufacturer's wholesale incomes in the traditional channel, which means $\pi_{T} \geq \gamma(w-c) Q_{t}$, then retailer is faced with advantageous channel unfairness. In this case, the retailer's perceived fairness utility is $-\beta\left[\pi_{T}-\gamma(w-c) Q_{t}\right]$ and its pricing decision problem can be described as

$$
\begin{array}{ll}
\max _{p_{t}} & U_{T}=\pi_{T}+f_{T} \\
\text { s.t. } & \pi_{T}=Q_{t}\left(p_{t}-w-C_{t}\right) \\
& f_{T}=-\beta\left[\pi_{T}-\gamma(w-c) Q_{t}\right] \\
& Q_{t}\left(p_{t}-w-C_{t}\right) \geq \gamma(w-c) Q_{t} .
\end{array}
$$


Proposition 3. (1) When retailer encounters disadvantageous channel unfairness, if the wholesale price $w$ and the online channel price $p_{e}$ satisfy condition 1:

$$
w \geq \frac{(1+\alpha)\left(E-b_{1} C_{t}\right)+\gamma c b_{1}(2+\alpha)+(1+\alpha) \xi p_{e}}{b_{1}(1+2 \gamma+\alpha+\alpha \gamma)},
$$

then retailer's optimal pricing strategy is $p_{t}^{f}=\left(E+b_{1} C_{t}+b_{1} w+\right.$ $\left.\xi p_{e}\right) / 2 b_{1}+\alpha \gamma(w-c) / 2(1+\alpha)$; if not, then the retailer's optimal pricing strategy is $p_{t}^{f}=(1+\gamma) w-\gamma c+C_{t}$.

(2) When retailer is faced with advantageous channel unfairness, if the wholesale price $w$ and the online channel price $p_{e}$ satisfy condition 2:

$$
w \leq \frac{(1-\beta)\left(E-b_{1} C_{t}\right)+\gamma c b_{1}(2-\beta)+(1-\beta) \xi p_{e}}{b_{1}(1+2 \gamma-\beta-\beta \gamma)}
$$

then retailer's optimal pricing strategy is $p_{t}^{f}=\left(E+b_{1} C_{t}+b_{1} w+\right.$ $\left.\xi_{p_{e}}\right) / 2 b_{1}-\beta \gamma(w-c) / 2(1-\beta)$; if not, then the retailer's optimal pricing strategy is $p_{t}^{f}=(1+\gamma) w-\gamma c+C_{t}$.

The proof of Proposition 3 is shown in Appendix B. To simplify the analysis, let

$$
\begin{gathered}
J_{1}=\frac{(1+\alpha)\left(E-b_{1} C_{t}\right)+\gamma c b_{1}(2+\alpha)}{b_{1}(1+2 \gamma+\alpha+\alpha \gamma)}, \\
J_{2}=\frac{(1-\beta)\left(E-b_{1} C_{t}\right)+\gamma c b_{1}(2-\beta)}{b_{1}(1+2 \gamma-\beta-\beta \gamma)}, \\
K_{1}=\frac{(1+\alpha) \xi}{b_{1}(1+2 \gamma+\alpha+\alpha \gamma)}, \\
K_{2}=\frac{(1-\beta) \xi}{b_{1}(1+2 \gamma-\beta-\beta \gamma)} .
\end{gathered}
$$

Then condition 1 becomes $w \geq J_{1}+K_{1} p_{e}$, and condition 2 becomes $w \leq J_{2}+K_{2} p_{e}$. It is trivial to prove that $J_{j}>0$, $K_{j}>0(j=1,2), J_{1}>J_{2}>0$, and $1>K_{1}>K_{2}>0$.

According to condition 1, condition 2, and the hypothesis $p_{e} \leq \widehat{p}_{e} \triangleq\left(\xi E+b_{1} F\right) /\left(b_{1} b_{2}-\xi^{2}\right)$, retailer's pricing decision region can be divided into the following three parts:

$$
\begin{gathered}
\text { Region } R_{1}=\left\{\left(p_{e}, w\right) \mid w \geq J_{1}+K_{1} p_{e}, w \leq p_{e} \leq \widehat{p}_{e}\right\} ; \\
\text { Region } R_{2}=\left\{\left(p_{e}, w\right) \mid J_{2}+K_{2} p_{e}<w<J_{1}+K_{1} p_{e}\right. \\
\left.w \leq p_{e} \leq \widehat{p}_{e}\right\} ;
\end{gathered}
$$

Region $R_{3}=\left\{\left(p_{e}, w\right) \mid w \leq J_{2}+K_{2} p_{e}, w \leq p_{e} \leq \widehat{p}_{e}\right\}$.
Proposition 4. Considering channel fairness, given manufacturer's pricing strategy $\left(p_{e}, w\right)$, retailer's optimal pricing option is

$$
p_{t}^{f}= \begin{cases}\frac{E+b_{1} C_{t}+b_{1} w+\xi p_{e}}{2 b_{1}}+\frac{\alpha \gamma(w-c)}{2(1+\alpha)}, & \left(p_{e}, w\right) \in R_{1} \\ (1+\gamma) w-\gamma c+C_{t}, & \left(p_{e}, w\right) \in R_{2} \\ \frac{E+b_{1} C_{t}+b_{1} w+\xi p_{e}}{2 b_{1}}-\frac{\beta \gamma(w-c)}{2(1-\beta)}, & \left(p_{e}, w\right) \in R_{3} .\end{cases}
$$

From Proposition 4 we can see that, in region $R_{2}$, when wholesale price is moderate, retailer's traditional channel pricing will not be affected by manufacturer's online price. And the optimal price of retailer is cost-based. In region $R_{1}$ as manufacturer offers high wholesale price, retailer encounters disadvantageous channel unfairness and will price $p_{t}^{f}\left(p_{t}^{f}=\right.$ $\left.\left(E+b_{1} C_{t}+b_{1} w+\xi p_{e}\right) / 2 b_{1}+\alpha \gamma(w-c) / 2(1+\alpha)\right)$ higher than the optimal traditional channel price $p_{t}^{*}$ without considering channel fairness $\left(p_{t}^{*}=\left(E+b_{1} C_{t}+b_{1} w+\xi p_{e}\right) / 2 b_{1}\right)$ to the manufacturer; but in region $R_{3}$ with low wholesale price, retailer is faced with advantageous channel unfairness, and for the consideration of fairness, retailer will set a lower price $\left(p_{t}^{f}=\left(E+b_{1} C_{t}+b_{1} w+\xi p_{e}\right) / 2 b_{1}-\beta \gamma(w-c) / 2(1-\beta)\right)$ than $p_{t}^{*}$ to compensate manufacturer with more offline sales. Overall, the effort of rewarding compensation and resisting punishment is proportional to the distribution of profits $\gamma$ of traditional channel.

4.2. Manufacturer's Pricing Decision Problem. Given retailer's optimal pricing response $p_{t}^{f}$ in the above three regions, manufacturer would determine the optimal wholesale price $w^{f}$ and online direct selling price $p_{e}^{f}$ in order to maximize its profit function $\pi_{M}=Q_{e}\left(p_{e}-C_{e}-c\right)+Q_{t}(w-c)$. Next, we discuss the manufacturer's pricing decision problem for each region.

(1) In region $R_{1}$, the manufacturer's pricing decision problem can be described as formula (21). Denote equilibrium price combination by $\left(p_{e 1}^{f}, w_{1}^{f}\right)$ and the optimal profit by $\pi_{M 1}^{f}$ :

$$
\begin{array}{cl}
\max _{p_{e}, w} & \pi_{M}=Q_{e} \cdot\left(p_{e}-C_{e}-c\right)+Q_{t} \cdot(w-c) \\
\text { s.t. } & p_{t}^{f}=\frac{E+b_{1} C_{t}+b_{1} w+\xi p_{e}}{2 b_{1}}+\frac{\alpha \gamma(w-c)}{2(1+\alpha)}, \\
& w \geq J_{1}+K_{1} p_{e}, \quad w \leq p_{e}, \quad p_{e} \leq \widehat{p}_{e} .
\end{array}
$$

(2) In region $R_{2}$, the manufacturer's pricing decision problem can be described as formula (22). Denote equilibrium price combination by $\left(p_{e 2}^{f}, w_{2}^{f}\right)$ and the optimal profit by $\pi_{M 2}^{f}$ :

$$
\begin{aligned}
\max _{p_{e}, w} & \pi_{M}=Q_{e} \cdot\left(p_{e}-C_{e}-c\right)+Q_{t} \cdot(w-c) \\
\text { s.t. } & p_{t}^{f}=(1+\gamma) w-\gamma c+C_{t} \\
& w>J_{2}+K_{2} p_{e}, \quad w<J_{1}+K_{1} p_{e} \\
& w \leq p_{e}, \quad p_{e} \leq \widehat{p}_{e} .
\end{aligned}
$$


(3) In region $R_{3}$, the manufacturer's pricing decision problem can be described as formula (23). Denote equilibrium price combination by $\left(p_{e 3}^{f}, w_{3}^{f}\right)$ and the optimal profit by $\pi_{M 3}^{f}$ :

$$
\begin{array}{ll}
\max _{p_{e}, w} & \pi_{M}=Q_{e} \cdot\left(p_{e}-C_{e}-c\right)+Q_{t} \cdot(w-c) \\
\text { s.t. } & p_{t}^{f}=\frac{E+b_{1} C_{t}+b_{1} w+\xi p_{e}}{2 b_{1}}-\frac{\beta \gamma(w-c)}{2(1-\beta)} \\
& w \leq J_{2}+K_{2} p_{e}, \quad w \leq p_{e}, \quad p_{e} \leq \widehat{p}_{e} .
\end{array}
$$

Ultimately, the largest global profit of manufacturer $\pi_{M}^{f}=$ $\max \left\{\pi_{M 1}^{f}, \pi_{M 2}^{f}, \pi_{M 3}^{f}\right\}$ is corresponding to the equilibrium price strategy, which decides the global optimum equilibrium strategy $\left(p_{e}^{f}, w^{f}\right)$. Substituting the equilibrium solution $\left(p_{e}^{f}, w^{f}\right)$ into formula (20), we get the retailer's optimal pricing strategy with the consideration of fairness. Then iterate the demand formulas (1) and (2) and retailer's profit formula (6) until the retailer's optimal profit $\pi_{T}^{f}$ can be obtained.

\section{Illustrative Examples}

Since the objective function and the optimal decision variables contain many parameters and complex expressions, we illustrate propositions and deductions in this paper with the aid of numerical example simulations to get insight into the enlightenment of management. We set basic values of the various parameters as $a=1, \phi=0.5, b_{1}=0.8, b_{2}=1$, $\xi=0.4, c=0.5, s_{t}=0.8$, and $s_{e}=0.4$. Referring to the empirical results in Fehr and Schmidt [14] and Xing et al. [16], we set the fairness parameter values $\alpha=1, \beta=0.4$, and $\lambda=0.7$. Considering the fairness effect on the result of supply chain members' decision-making, we select $\mu_{t}=\mu_{e}=0.2$ and change service level to reflect the variation of free-riding effect for simplicity.

5.1. Impact of Online Channel Market Share. Let the range of market share $\phi$ of online channel be from 0.1 to 0.9 , and let other parameters be on basic values. Figures 1 and 2 reflect the effect that online market share and channel fairness have on manufacturer and traditional retailer's pricing decisions and profit results.

From Figures 1 and 2 we know that the retailer's profits in the situation of considering fairness are always higher than those of ignoring fairness $\left(\pi_{T}^{f}>\pi_{T}\right)$. When online market share $\phi$ is in the range of 0.75 to 0.9 , retailer faces disadvantageous channel unfairness and will negatively increase the price $\left(p_{t}^{f}>p_{t}\right)$ against the manufacturer's oppression. In the end, it makes the performance of manufacturer and supply chain lower than that of the situation of not considering fairness $\left(\pi_{M}^{f}<\pi_{M}, \pi^{f}<\pi\right)$. When online market share $\phi$ is about 0.1 to 0.7 , retailer faces advantageous channel unfairness and will reduce the price of traditional channel $\left(p_{t}^{f}<p_{t}\right)$ to increase the traditional channel demand. In that case, although the manufacturer's profits decline, channel fairness significantly improves the performance level of the

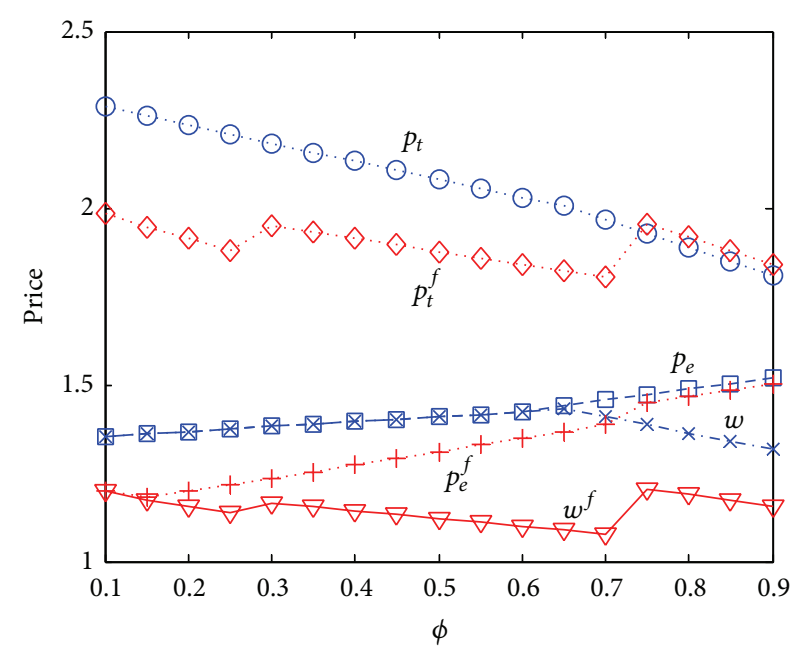

FIGURE 1: The effect of market share and channel on price.

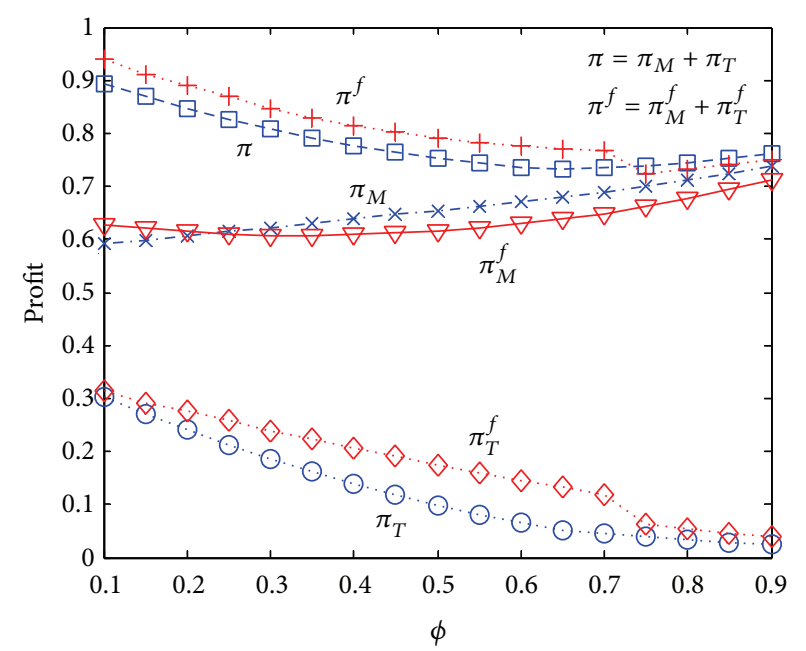

FIGURE 2: The effect of market share and channel fairness on profit.

supply chain $\left(\Delta \pi=\pi^{f}-\pi>0\right)$. If manufacturer designs appropriate mechanism to coordinate dual-channel supply chain in consideration of fairness, then both the supply chain members will achieve Pareto improvement of higher income than otherwise. Among the appropriate contracts, there is a revenue sharing contract of bargaining [23] such that $\Delta \pi_{T}=$ $A /(A+B) \Delta \pi>0$ and $\Delta \pi_{M}=B /(A+B) \Delta \pi>0$, where the values of $A$ and $B$ are determined by the bargaining power between the two sides. Finally we obtain $\pi_{T}^{\prime}=\Delta \pi_{T}+\pi_{T}$ and $\pi_{M}^{\prime}=\Delta \pi_{M}+\pi_{M}$ and realize win-win results of dual-channel supply chain.

From Figure 1 we can see that when online market share of manufacturer is larger, it will adopt a lower wholesale price to maintain the traditional channel operation of retailer and provide a quality experience for online consumers no matter whether they take retailer's channel fairness into account or not. Thereby, utilize free-riding behavior to further improve the attractiveness of the online channel indirectly. Overall, manufacturer's equilibrium price concerned with channel fairness will be obviously lower than that of not considering channel fairness. 


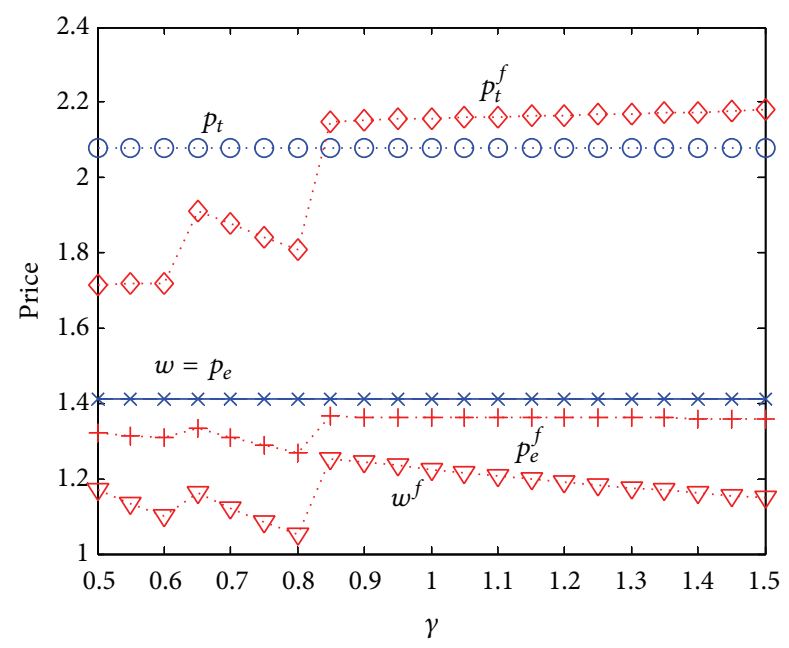

FIGURE 3: Effect of fairness channel profit distribution on channel pricing.

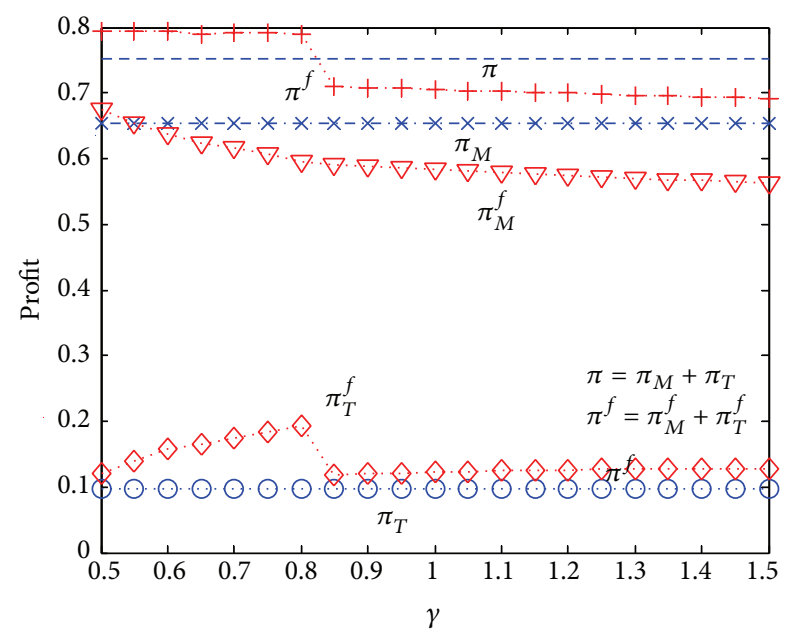

FIGURE 4: Effect of fairness channel profit distribution on channel profits.

5.2. Effect of Fairness Channel Profit Distribution. Figures 3 and 4 reflect the trends of equilibrium prices of manufacturer and retailer and optimal profits with the changing of fairness channel profit distribution $\gamma$.

From Figure 3 we can see that if fairness is considered, the manufacturer's equilibrium prices are always lower than otherwise $\left(p_{e}^{f}<p_{e}\right)$. When profit distribution $\gamma$ is in the range of 0.5 to 0.85 , retailer faces advantageous channel unfairness. In that case, with the value of parameter $\gamma$ becoming larger, retailer will increase the traditional channel price, while manufacturer reduces the wholesale price to achieve channel fairness. It makes retailer's profits in Figure 4 significantly higher than those of not considering fairness $\left(\pi_{T}^{f}>\pi_{T}\right)$. But it causes some loss to manufacturer. However, retailer's increased profits are far more than manufacturer's decreased profits. Overall, the performance of supply chain is obviously enhanced in the end $\left(\pi^{f}>\pi\right)$. In the above situation of

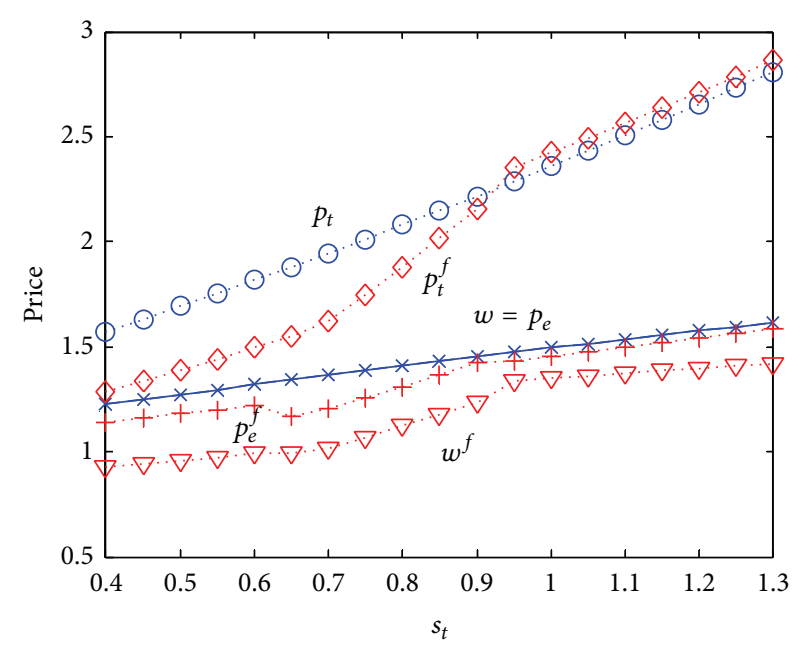

FIGURE 5: Effect of service level and free-riding on channel pricing.

considering fairness, if manufacturer designs an appropriate dual-channel contract mechanism which coordinates the profit distribution problem, then they both will achieve a winwin situation. When $\gamma$ increases from 0.85 to 1.5 , retailer will face disadvantageous channel unfairness. In such traditional channel profits sharing goal, manufacturer will improve its pricing level in order to suppress the retailer's ambition of earning profits in the traditional channel; at the same time retailer also increases the traditional channel price $p_{t}^{f}$ rapidly, significantly higher than that of without considering fairness $\left(p_{t}^{f}>p_{t}\right)$. The retailer's profits in Figure 4 are higher than its profits of not considering fairness. But due to the retailer's price increasing resistance, the demand of traditional channel reduces. Eventually it leads to the declination of manufacturer and supply chain's profits which are significantly lower than that of not considering fairness.

Overall, taking fairness into consideration, the retailer's profits are always higher than those of not considering fairness $\left(\pi_{T}^{f}>\pi_{T}\right)$ and its maximum profit is attainable when $\gamma=0.8$. But the comparison results of manufacturer's profits are on the contrary $\left(\pi_{M}^{f}<\pi_{M}\right)$. But the total profits of the supply chain with considering fairness and not considering fairness have relation to the profits distribution $\gamma$ which is a ratio among fairness parameters, namely, retailer's goal to reach the target profits from traditional channel compared with manufacturer. When $\gamma$ is small, the total profits of the supply chain with considering fairness are bigger than those of without considering fairness. Thus manufacturer can design appropriate contract to coordinate the dual-channel for achieving win-win situation. When $\gamma$ is bigger, the total profits of the supply chain without considering fairness will be bigger. In that case, the manufacturer will choose to ignore retailer's concern of channel fairness.

5.3. The Effect of Service Level and Free-Riding. Figures 5 and 6 reflect the effect of service level on equilibrium prices and profits of manufacturer and retailer. As free-riding behavior based on channel service exists between channels, we analyze 


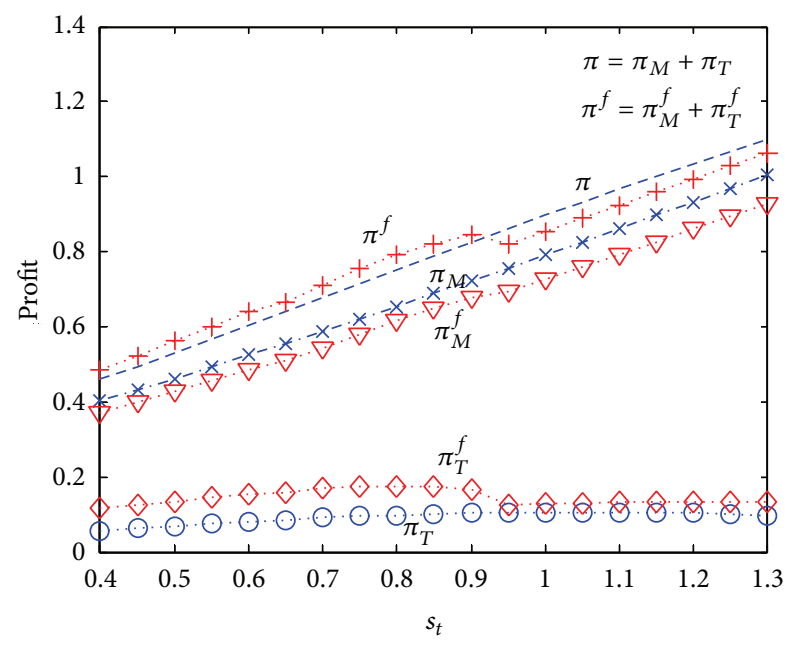

FIGURE 6: Effect of service level and free-riding on profit.

the impact of free-riding on dual-channel pricing decision with considering fairness through discussing the change of service level for simplicity.

Figure 5 shows that, with fairness consideration, manufacturer's equilibrium price $\left(p_{e}^{f}, w^{f}\right)$ is lower than the price strategy $\left(p_{e}, w\right)$ under situation of not considering channel fairness. When the service level provided by traditional retailer is lower, retailer faces advantageous channel unfairness. In that case, retailer's equilibrium price $p_{t}^{f}$ is far lower than $p_{t}$. With the improvement of service level, $p_{t}^{f}$ increases more precipitously than $p_{t}$. When the service level of traditional channel is high, retailer faces disadvantageous channel unfairness. Because manufacturer takes more freeriding from traditional channel to profit, retailer does not reach profits distribution goal at traditional channel. For the retailer's consideration of channel fairness, it will set $p_{t}^{f}$ higher than $p_{t}$ that not considering fairness to boycott manufacturer. This measure makes manufacturer's profits in Figure 6 decline larger and also makes the overall performance of the supply chain worse than that of not considering fairness.

Overall, from Figure 6 we know that after considering fairness, retailer's profits increase while manufacturer's profits decline. The improvement of traditional service level can increase the demand of traditional channel. But taking freeriding effect into account, the online channel free-riding effect is far beyond traditional channel's $\left(\mu_{e} s_{t}>\mu_{t} s_{e}\right)$. Thus manufacturer's profits increase with the improvement of traditional service level, while retailer's profits present the trend of first increasing and then decreasing because of the balance between service cost and benefit. When service level of traditional channel is about between 0.8 and 0.9 , retailer and supply chain system both reach their peak profits. In order to achieve win-win solution among supply chain members, retailer should choose a moderate service level. In that case, with fairness consideration, if manufacturer adopts certain measures to share the additional profits with retailer, then the Pareto improvement of dual-channel supply chain will be able to be achieved.

\section{Conclusions}

Dual-channel structure studied in this paper includes horizontal competition between traditional channel and online channel and vertical competition between the upstream and downstream supply chain. In addition, free-riding effect that causes the imbalance of profits distribution between manufacturer and retailer is inevitable in dual-channel structure, and channel unfair phenomenon is outstanding. Combining with free-riding behavior, this paper builds a linear demand function and uses fairness revised price game model to discuss pricing strategy and revenue performance of manufacturer and retailer. Finally, from numerical analysis, we provide management recommendations for manufacturer and retailer.

Our research finds that when manufacturer's online market share is large enough, whether considering retailer's channel fairness or not, due to free-riding effect, manufacturer will always lower wholesale price in order to maintain retailer's traditional channel operation and provide quality experience service for its consumers. But as traditional channel enhances service level, online channel takes much more service freeriding from traditional channel than what traditional channel takes on the opposite. Therefore, manufacturer gains increase with the service improvement of traditional channel, the retailer profits first increase and then decrease. In short, manufacturer's equilibrium price based on channel fairness is below its equilibrium price ignoring fairness. Manufacturer is willing to lose some profits in order to achieve channel fairness, and at the same time retailer always gets more profits in fairness considering situation.

There are two channel unfairness cases that retailer faced, disadvantageous channel unfairness and advantageous channel unfairness. When retailer faces disadvantageous channel unfairness, retailer's profits gained from fairness consideration could not make up manufacturer's profits difference compared with ignoring channel fairness. In such case, taking fairness into account will make supply chain performance worse, and there is no contract that could coordinate the supply chain, so manufacturer would like to ignore channel fairness. However, when retailer encounters advantageous channel unfairness phenomenon, retailer revenue increase was significantly greater than the reduction in the earnings of manufacturers due to fairness consideration, which leads to performance improvement of supply chain. In this state, if manufacturer considers channel fairness and designs appropriate revenue sharing contract to coordinate profits distribution, the supply chain members would realize the Pareto improvement.

However, there are still some limitations in this paper. Firstly, we only analyze retailer's fairness preference and assume that manufacturer is a rational decision maker. But in reality, manufacturer may also have channel fairness preference. In addition, under certain conditions, supply chain decision performance with fairness consideration still does not reach the optimal value of centralized decisionmaking. Therefore, the future may continue to study how could manufacturer design appropriate contract mechanism to coordinate the dual-channel supply chain when a variety 
of behavioral factors are concerned. At last, the topic of this paper comes from the actual market research, but we have limitation of the availability of great empirical data. As a result of empirical data limitation, we use mathematical derivation and numerical simulation methods to solve the problem and seek management proposals. If more field research data can be collected in the future, such dual-channel management research based on behavioral factors would make a big breakthrough.

\section{Appendices}

\section{A. The Manufacturer Equilibrium Pricing without considering Fairness}

Manufacturer's decision problem is as follows:

$$
\begin{array}{ll}
\max _{p_{e}, w} & \pi_{M}=Q_{e} \cdot\left(p_{e}-C_{e}-c\right)+Q_{t} \cdot(w-c) \\
\text { s.t. } & p_{e} \geq w \\
& Q_{t}=(1-\phi) a-b_{1} p_{t}+\xi_{1} p_{e}+s_{t}+\mu_{t} s_{e} \\
& Q_{e}=\phi a-b_{2} p_{e}+\xi_{2} p_{t}+s_{e}+\mu_{e} s_{t} .
\end{array}
$$

With known $E=(1-\phi) a+s_{t}+\mu_{t} s_{e}, F=\phi a+s_{e}+\mu_{e} s_{t}$, to profit function $\pi_{M}$, the first-order partial derivatives of online channel price $p_{e}$ and wholesale price $w$ are

$$
\begin{aligned}
\frac{\partial \pi_{M}}{\partial w}= & -b_{1} w+\xi p_{e} \\
& +\frac{\left(b_{1}-\xi\right) c+E-b_{1} C_{t}-\xi C_{e}}{2}, \\
\frac{\partial \pi_{M}}{\partial p_{e}}= & \xi w+\frac{\xi^{2}-2 b_{1} b_{2}}{2 b_{1}}\left(2 p_{e}-C_{e}\right) \\
& +\frac{\left(2 b_{1} b_{2}-\xi^{2}-b_{1} \xi\right) c+\xi E+b_{1} \xi C_{t}}{2 b_{1}}+F
\end{aligned}
$$

The second-order partial derivatives are

$$
\begin{array}{cc}
\frac{\partial \pi_{M}^{2}}{\partial w^{2}}=-b_{1}, & \frac{\partial \pi_{M}^{2}}{\partial p_{e}^{2}}=\frac{\xi^{2}-2 b_{1} b_{2}}{b_{1}}, \\
\frac{\partial \pi_{M}^{2}}{\partial w \partial p_{e}}=\xi, & \frac{\partial \pi_{M}^{2}}{\partial p_{e} \partial w}=\xi .
\end{array}
$$

So the Hessian matrix of the profit function $\left|\begin{array}{cc}-b_{1} & \xi \\ \xi & \left(\xi^{2}-2 b_{1} b_{2}\right) / b_{1}\end{array}\right|$ is negative definite. Profit function is a concave function of online channel price $p_{e}$ and wholesale price $w$ and exists in unique equilibrium solution. The manufacturer decision problem is transformed into Karush-Kuhn-Tucker optimization conditions as follows:

$$
\begin{gathered}
-b_{1} w+\xi p_{e}+\frac{\left(b_{1}-\xi\right) c+E-b_{1} C_{t}-\xi C_{e}}{2}-\lambda=0 \\
\xi w+\frac{\xi^{2}-2 b_{1} b_{2}}{2 b_{1}}\left(2 p_{e}-C_{e}\right) \\
+\frac{\left(2 b_{1} b_{2}-\xi^{2}-b_{1} \xi\right) c+\xi E+b_{1} \xi C_{t}}{2 b_{1}}+F+\lambda=0 \\
\lambda\left(p_{e}-w\right)=0, \quad \lambda \geq 0, \quad p_{e} \geq w
\end{gathered}
$$

(1) When $\lambda=0$,

$$
\begin{gathered}
p_{e}^{*}=\frac{\xi E+b_{1} F}{2\left(b_{1} b_{2}-\xi^{2}\right)}+\frac{c+C_{e}}{2}, \\
w^{*}=\frac{b_{2} E+\xi F+\left(\left(\xi^{3}-b_{1} b_{2} \xi\right) / b_{1}\right) C_{e}}{2\left(b_{1} b_{2}-\xi^{2}\right)}+\frac{c-C_{t}}{2} .
\end{gathered}
$$

(2) When $\lambda>0$,

$$
\begin{aligned}
p_{e}^{*}=w^{*}= & \left(\left(b_{1}+\xi\right) E+2 b_{1} F+b_{1}\left(\xi-b_{1}\right) C_{t}\right. \\
& \left.+\left(2 b_{1} b_{2}-\xi^{2}-b_{1} \xi\right) C_{e}\right) \\
& \left.\times\left(2\left(b_{1}^{2}+2 b_{1} b_{2}-\xi^{2}-2 b_{1} \xi\right)\right)^{-1}\right)+\frac{c}{2}, \\
\lambda= & \left(\left(\xi^{2}+b_{1} \xi-b_{1} b_{2}-b_{1}^{2}\right) E+b_{1}\left(\xi-b_{1}\right) F\right. \\
& \left.+2 b_{1}^{2}\left(b_{2}-2 \xi\right) C_{t}+b_{1}\left(\xi^{2}-b_{1} b_{2}\right) C_{e}\right) \\
& \times\left(b_{1}^{2}+2 b_{1} b_{2}-\xi^{2}-2 b_{1} \xi\right)^{-1} .
\end{aligned}
$$

For $\lambda>0$ and in the text parameter assumptions conditions, we have

$$
\begin{aligned}
\phi<\widehat{\phi} \triangleq & \left(\left(b_{2}-\xi\right)\left(a+s_{t}+\mu_{t} s_{e}\right)+\left(\xi-b_{1}\right)\left(s_{e}+\mu_{e} s_{t}\right)\right. \\
& \left.+\left(\xi^{2}-b_{1} b_{2}\right)\left(C_{t}-C_{e}\right)\right) \\
& \times\left(a\left(b_{1}+b_{2}-2 \xi\right)\right)^{-1} .
\end{aligned}
$$

\section{B. Channel Pricing Strategy considering Fairness}

(1) Retailer faces disadvantageous channel unfairness. The decision problem is

$$
\begin{array}{ll}
\max _{p_{t}} & U_{T}=\pi_{T}+f_{T} \\
\text { s.t. } & \pi_{T}=Q_{t}\left(p_{t}-w-C_{t}\right) \\
& f_{T}=-\alpha\left[\gamma(w-c) Q_{t}-\pi_{T}\right] \\
& \gamma(w-c) Q_{t} \geq Q_{t}\left(p_{t}-w-C_{t}\right) .
\end{array}
$$


Using Karush-Kuhn-Tucker method, the above problem can be converted to the following optimization problem:

$$
\begin{array}{cc}
\max _{p_{t}, \lambda_{1}} & L_{1}\left(p_{t}, \lambda_{1}\right)=Q_{t}(1+\alpha)\left(p_{t}-w-C_{t}\right)-\alpha \gamma Q_{t}(w-c) \\
& +\lambda_{1}\left[(1+\gamma) w-\gamma c+C_{t}-p_{t}\right] \\
\text { s.t. } & Q_{t}=E-b_{1} p_{t}+\xi p_{e} \\
& \lambda_{1}\left[(1+\gamma) w-\gamma c+C_{t}-p_{t}\right]=0 \\
(1+\gamma) w-\gamma c+C_{t}-p_{t} \geq 0 \\
\lambda_{1} \geq 0 .
\end{array}
$$

The KKT conditions are as follows:

$$
\begin{gathered}
\frac{\partial L_{1}}{\partial p_{t}}=\left(E-b_{1} p_{t}+\xi_{p}\right)(1+\alpha)-b_{1}(1+\alpha)\left(p_{t}-w-C_{t}\right) \\
+b_{1} \alpha \gamma(w-c)-\lambda_{1}=0, \\
\lambda_{1}\left[(1+\gamma) w-\gamma c+C_{t}-p_{t}\right]=0, \\
(1+\gamma) w-\gamma c+C_{t}-p_{t} \geq 0, \\
\lambda_{1} \geq 0 .
\end{gathered}
$$

(i) When $\lambda_{1}=0$, obtain $p_{t}^{f}=\left(E+b_{1} C_{t}+b_{1} w+\xi p_{e}\right) / 2 b_{1}+$ $\alpha \gamma(w-c) / 2(1+\alpha)$; substituting inequality $(1+\gamma) w-$ $\gamma c+C_{t}-p_{t} \geq 0$, get

$w \geq \frac{(1+\alpha)\left(E-b_{1} C_{t}\right)+\gamma c b_{1}(2+\alpha)+(1+\alpha) \xi p_{e}}{b_{1}(1+2 \gamma+\alpha+\alpha \gamma)}$.

(ii) When $\lambda_{1}>0$, obtain $p_{t}^{f}=(1+\gamma) w-\gamma c+C_{t}$.

Similar to the case of advantageous channel unfairness.

\section{Conflict of Interests}

The authors declare that there is no conflict of interests regarding the publication of this paper.

\section{Acknowledgments}

The authors are very grateful to the editor and the anonymous reviewers for their insightful and constructive comments and suggestions that have led to an improved version of this paper. This work was partially supported by the National Innovation Group Science Foundation, China (no. 71221061), International Major Project Supported by the National Natural Science Foundation, China (no. 71210003), the National Science Foundation of China (71271219 and 71071164), and Program for New Century Excellent Talents in University (NCET-11-0519).

\section{References}

[1] K. D. Cattani, W. G. Gilland, and J. M. Swaminathan, "Coordinating traditional and internet supply chains," in Handbook of Quantitative Supply Chain Analysis: Modeling in the EBusiness Era, International Series in Operations Research and Management Science, Kluwer Academic, Boston, Mass, USA, 2004.

[2] A. A. Tsay and N. Agrawal, "Modeling conflict and coordination in multi-channel distribution systems: a review," in Handbook of Quantitative Supply Chain Analysis: Modeling in the EBusiness Era, International Series in Operations Research and Management Science, Kluwer Academic, Boston, Mass, USA, 2004

[3] F. Wen and X. Yang, "Skewness of return distribution and coefficient of risk premium," Journal of Systems Science and Complexity, vol. 22, no. 3, pp. 360-371, 2009.

[4] F. Wen, Z. He, and X. Chen, "Investors' risk preference characteristics and conditional skewness," Mathematical Problems in Engineering, vol. 2014, Article ID 814965, 14 pages, 2014.

[5] O. P. Bomsel, "Free-riding and luxury brands on the internet," International Business Research, vol. 7, no. 4, pp. 60-71, 2014.

[6] S. van Baal and C. Dach, "Free riding and customer retention across retailers' channels," Journal of Interactive Marketing, vol. 19, no. 2, pp. 75-85, 2005.

[7] F. Wen, X. Gong, Y. Chao, and X. Chen, "The effects of prior outcomes on risky choice evidence from the stock market," Mathematical Problems in Engineering, vol. 2014, Article ID 272518, 8 pages, 2014.

[8] C. Huang, X. Gong, X. Chen, and F. Wen, "Measuring and forecasting volatility in chinese stock market using HAR-CJM model," Abstract and Applied Analysis, vol. 2013, Article ID 143194, 13 pages, 2013

[9] A. Rangaswamy and G. H. van Bruggen, "Opportunities and challenges in multichannel marketing: an introduction to the special issue," Journal of Interactive Marketing, vol. 19, no. 2, pp. 5-11, 2005.

[10] P. C. Verhoef, S. A. Neslin, and B. Vroomen, "Multichannel customer management: understanding the research-shopper phenomenon," International Journal of Research in Marketing, vol. 24, no. 2, pp. 129-148, 2007.

[11] D. Xing and T. Liu, "Sales effort free riding and coordination with price match and channel rebate," European Journal of Operational Research, vol. 219, no. 2, pp. 264-271, 2012.

[12] N. Kumar, L. K. Scheer, and J. B. E. M. Steenkamp, "The effects of supplier fairness on vulnerable resellers," Journal of Marketing Research, vol. 32, no. 1, pp. 54-65, 1995.

[13] N. Kumar, "The power of trust in manufacturer-retailer relationships," Harvard Business Review, vol. 74, no. 6, pp. 92-106, 1996.

[14] E. Fehr and K. M. Schmidt, "A theory of fairness, competition, and cooperation," The Quarterly Journal of Economics, vol. 114, no. 3, pp. 817-868, 1999.

[15] Y. Wu, C. H. Loch, and L. van der Heyden, "A model of fair process and its limits," Manufacturing \& Service Operations Management, vol. 10, no. 4, pp. 637-653, 2008.

[16] W. Xing, S.-Y. Wang, Q.-H. Zhao, and G.-W. Hua, "Impact of fairness on strategies in dual-channel supply chain," System Engineering Theory \& Practice, vol. 31, no. 7, pp. 1249-1256, 2011.

[17] T. H. Cui, J. S. Raju, and Z. J. Zhang, "Fairness and channel coordination," Management Science, vol. 53, no. 8, pp. 1303-1314, 2007. 
[18] T. H. Ho and J. Zhang, "Designing pricing contracts for boundedly rational customers: does the framing of the fixed fee matter?” Management Science, vol. 54, no. 4, pp. 686-700, 2008.

[19] O. Caliskan-Demirag, Y. Chen, and J. Li, "Channel coordination under fairness concerns and nonlinear demand," European Journal of Operational Research, vol. 207, no. 3, pp. 1321-1326, 2010.

[20] T.-H. Ho and X. Su, "Peer-induced fairness in games," American Economic Review, vol. 99, no. 5, pp. 2022-2049, 2009.

[21] X. Yue and J. Liu, "Demand forecast sharing in a dual-channel supply chain," European Journal of Operational Research, vol. 174, no. 1, pp. 646-667, 2006.

[22] A. A. Tsay and N. Agrawal, "Channel dynamics under price and service competition," Manufacturing \& Service Operations Management, vol. 2, no. 4, pp. 372-391, 2000.

[23] R. Yan, "Managing channel coordination in a multi-channel manufacturer-retailer supply chain," Industrial Marketing Management, vol. 40, no. 4, pp. 636-642, 2011. 


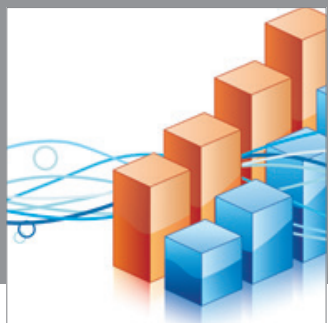

Advances in

Operations Research

mansans

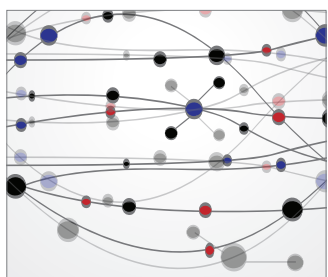

The Scientific World Journal
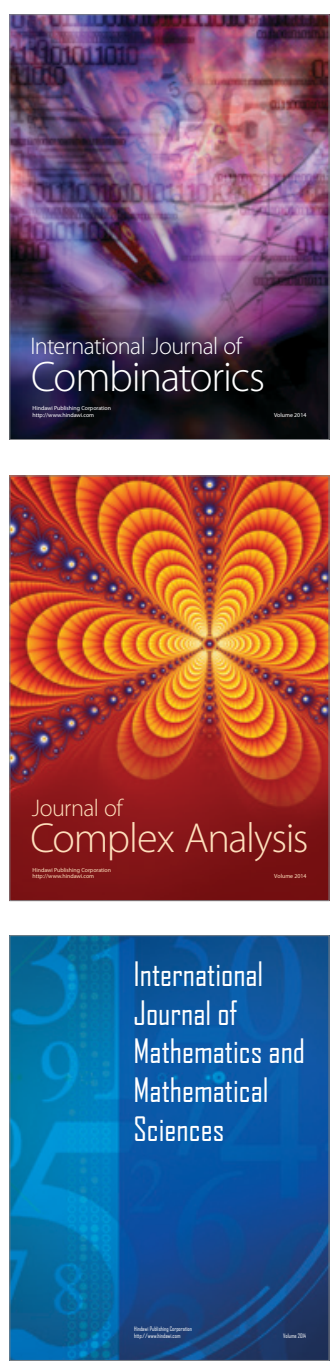
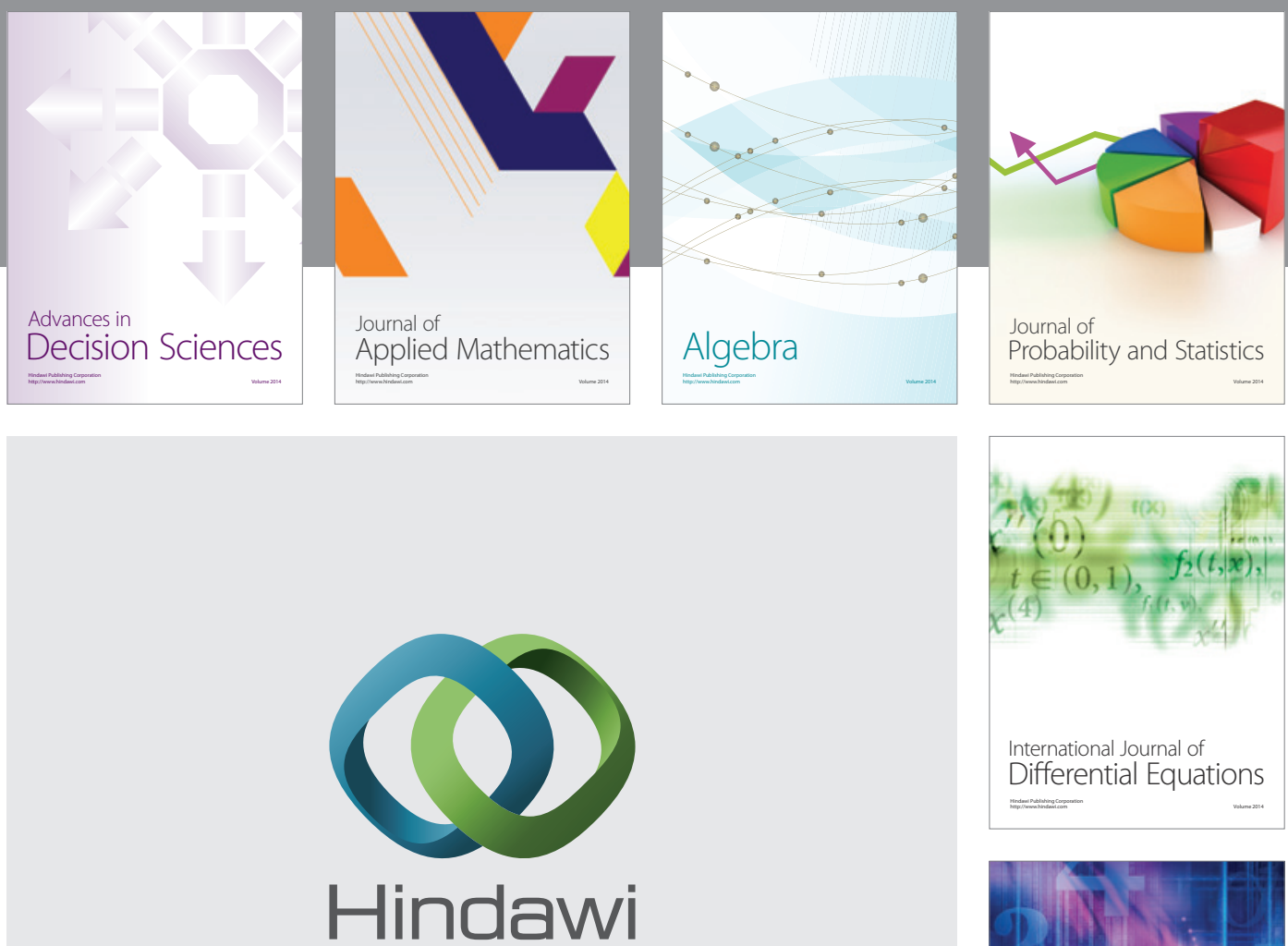

Submit your manuscripts at http://www.hindawi.com
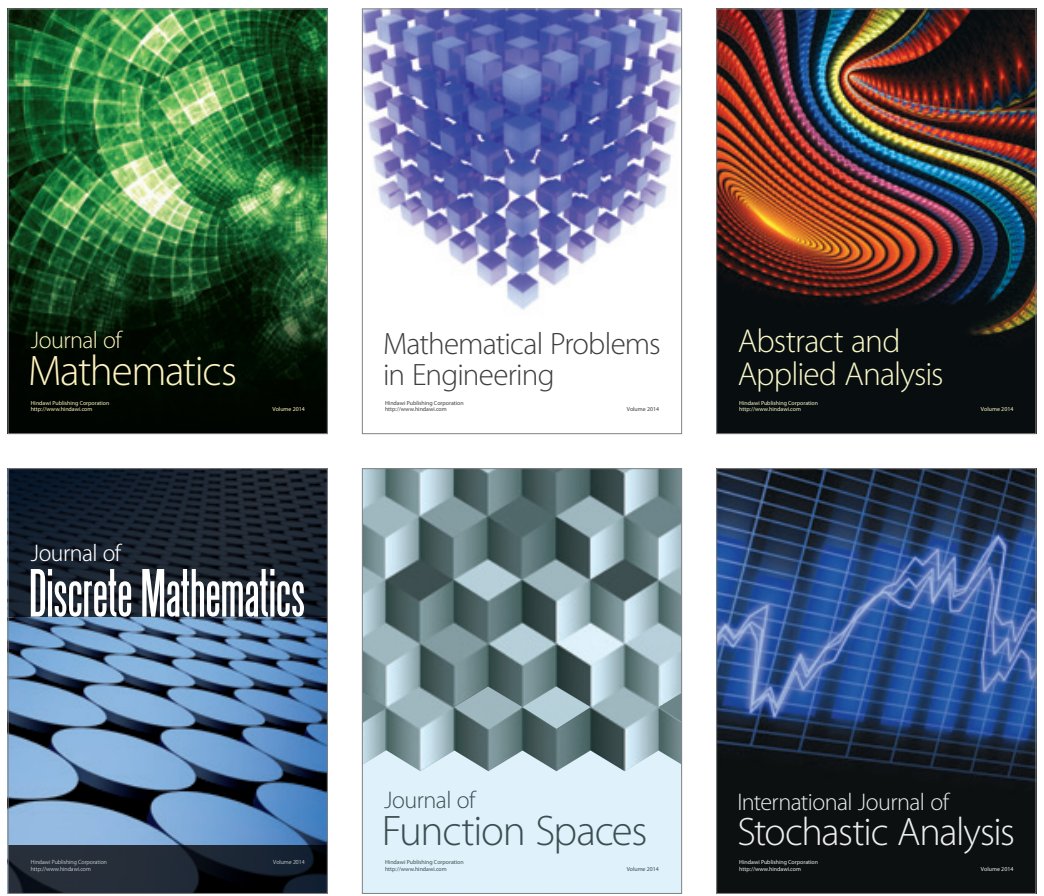

Journal of

Function Spaces

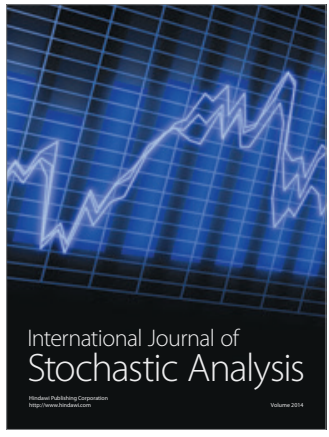

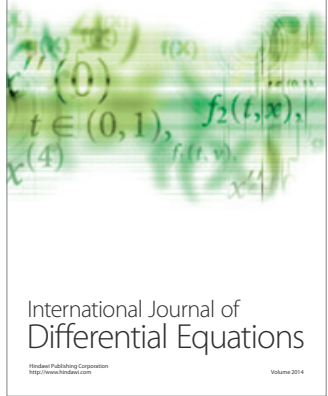
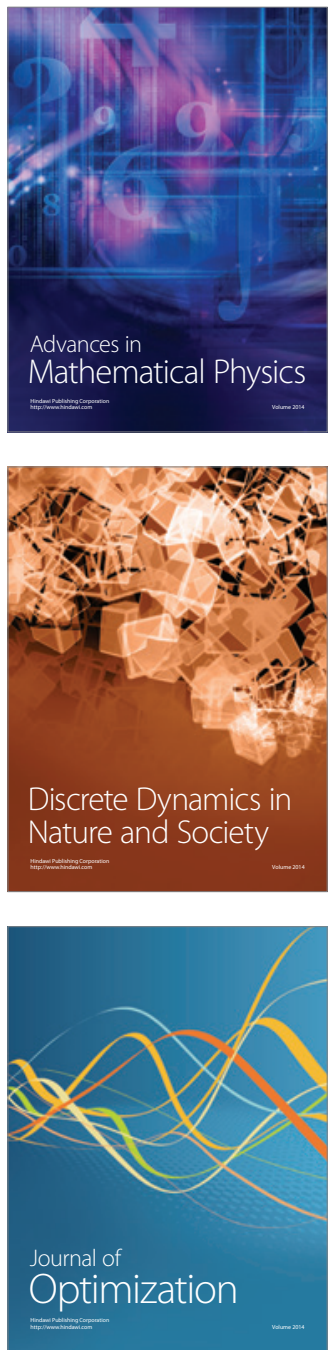